\section{Comment on Excited-State Acid-Base Kinetics and Equilibria in Norharmane}

A. P. Varela ${ }^{\ddagger}$ A. Dias, ${ }^{\dagger}$ M. da Graça Miguel,,$^{\ddagger}$

Ralph S. Becker, ${ }^{\dagger}$ and A. L. Maçanita ${ }^{*},{ }^{\dagger}, 8$

Instituto de Tecnologia Quimica e Biologica, Rua da Quinta Grande, 6, P-2780 Oeiras, Portugal; Departamento de

Quimíca, Universidade de Coimbra, Coimbra, Portugal; and Departamento de Química de I.S.T., Lisboa, Portugal

Received: June 30, 1994

We wish to briefly note significant errors in experimental data ${ }^{1}$ regarding lifetimes $\left(\tau_{\mathrm{F}}\right)$ of norharmane (Norh) both in organic solvents and as a function of $\mathrm{pH}$. This in turn affects the correctness of the determined rate constants, even presuming the model presented was correct. We shall discuss some on this latter point and more in a comprehensive paper on harmine (in preparation).

Experimental Data. We first noticed that the $\tau_{\mathrm{F}}$ of Norh in several organic solvents were in great disagreement with our and other authors' work published earlier, 3,4 yet this was not taken into consideration. In addition, we have determined the $\tau_{\mathrm{F}}$ in other solvents, and these are all compared in Table 1.

In Figure 1, the fluorescence decays of norharmane in $\mathrm{H}_{2} \mathrm{O}$, at $\mathrm{pH}=9.2$, at three emission wavelengths $-370 \mathrm{~nm}$ (neutral form), $450 \mathrm{~nm}$ (cation plus neutral), and $500 \mathrm{~nm}$ (mainly zwitterion, plus cation)-are shown, and the best fit parameters for single-, double-, and triple-exponential analysis are presented. It is clear that for $\lambda>400 \mathrm{~nm}$ three exponentials are necessary to fit the decays (see weighted residuals and $\chi^{2}$ ), and the decays at $450 \mathrm{~nm}$ are completely different from these at $550 \mathrm{~nm}$ with
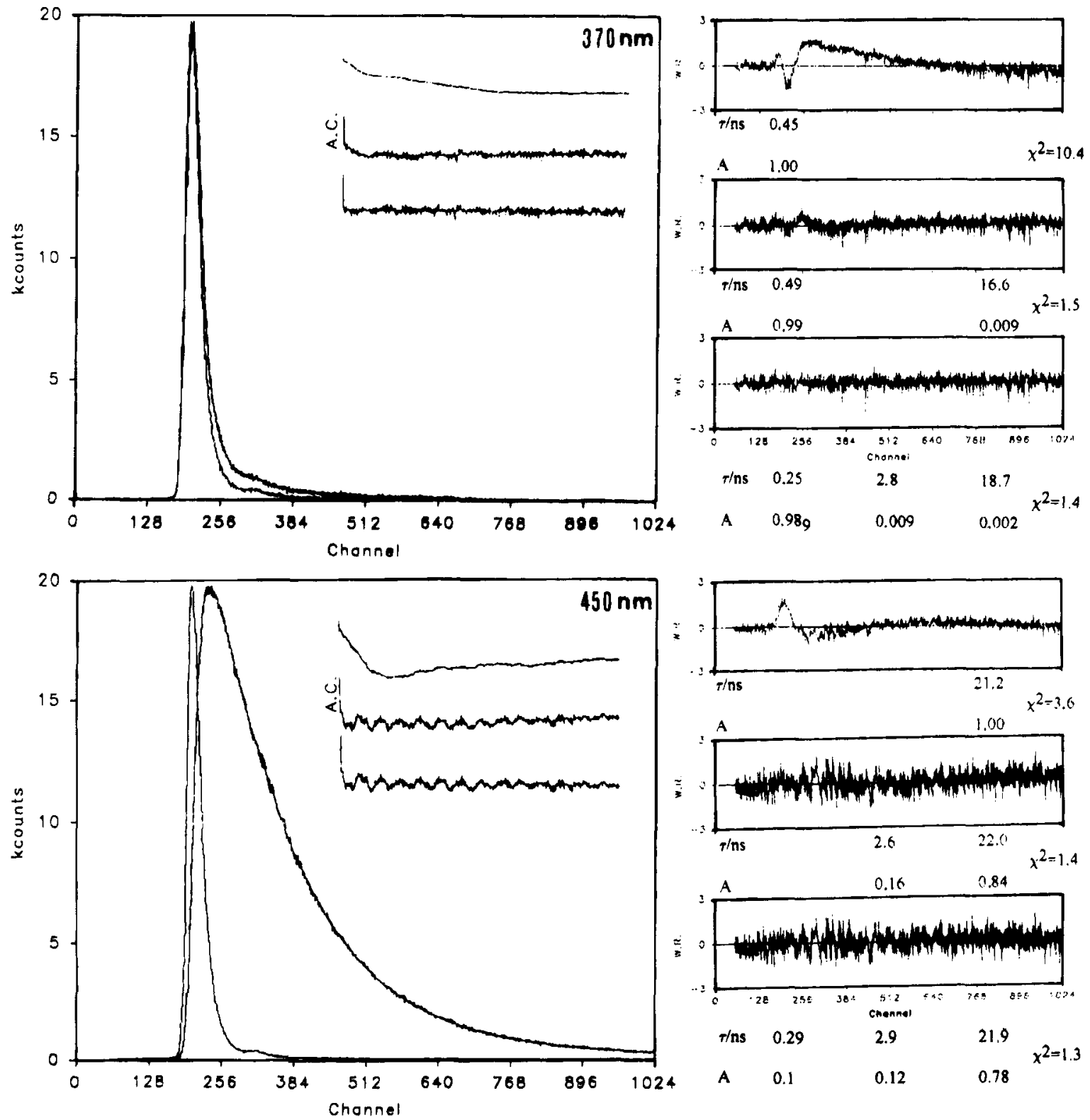

Figure 1. Fluorescence decays of norharmane in $\mathrm{H}_{2} \mathrm{O}\left(\mathrm{pH} \mathrm{9.2,T}=21^{\circ} \mathrm{C}\right)$ at 370,450 , and $550 \mathrm{~nm}$ and weighted residuals and autocorrelation functions for single-, double-, and triple-exponential analysis of the decays. 

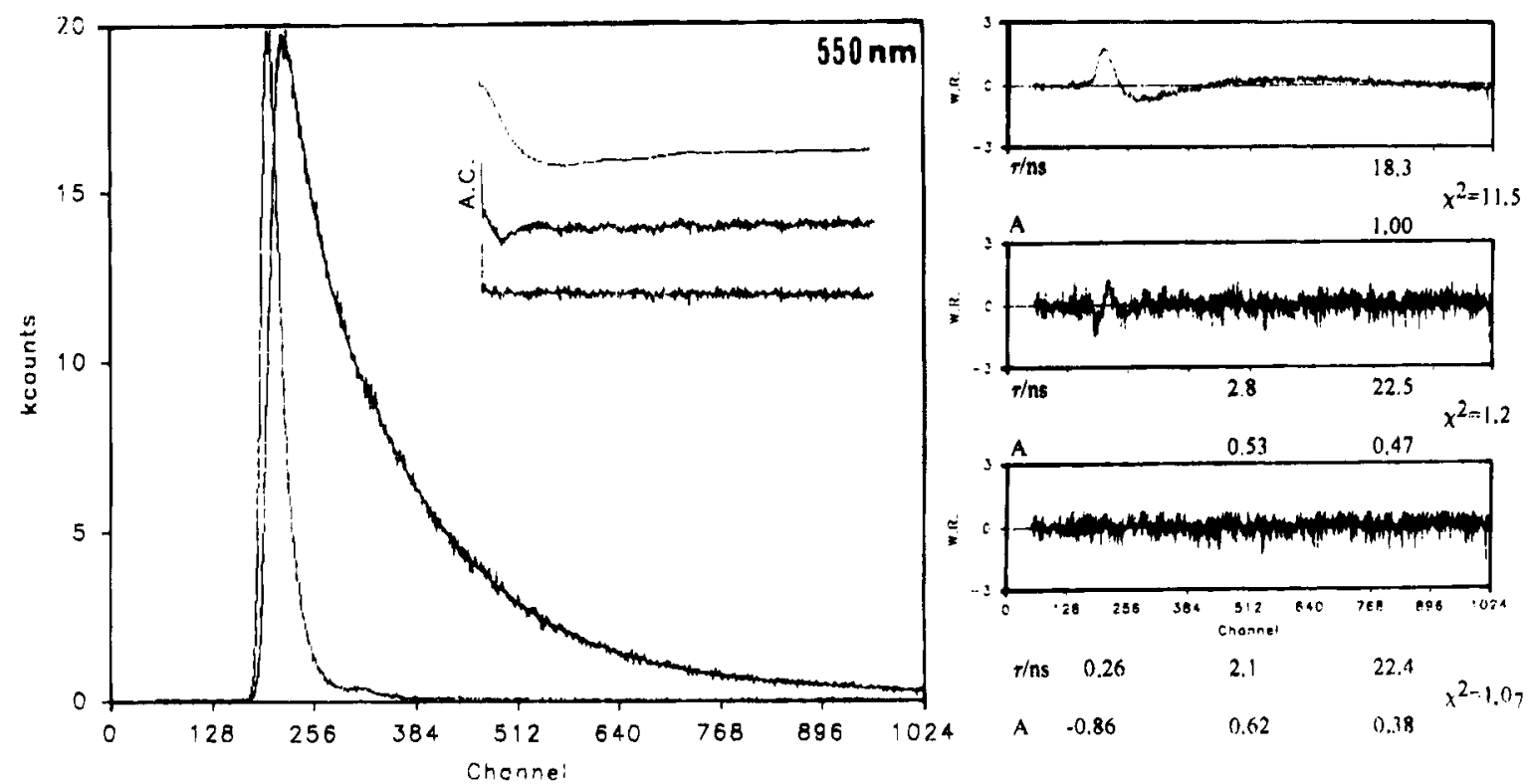

Figure 1 (Continued).

TABLE 1: Our Fluorescence Lifetimes from Single-Exponential Decays of Norharmane in Several Solvents at $21^{\circ} \mathrm{C}$ (Values in Parentheses from Ref 1)

\begin{tabular}{ccccc}
\hline & \multicolumn{4}{c}{ solvent } \\
\cline { 2 - 5 } & toluene & acetonitrile & ethanol & methanol \\
\hline$\tau / \mathrm{ns}$ & 3.4 & 3.8 & 5.8 & 2.8 \\
& $(8.1)$ & $(6.5)$ & $(16.4)$ & $(12.8)$
\end{tabular}

respect to the preexponential factors (see $A$ values). These observations are in marked contrast with the statement in ref 1 , "... for $\lambda>400 \ldots$ the decay is single exponential within the experimental accuracy and the decay time is independent of wavelength".

In Figure 2a, the $\mathrm{pH}$ dependence for the three decay times observed over the entire emission spectrum is shown. The two shortest decay times remain approximately constant from $\mathrm{pH}$ $=4$ to $12\left(\tau_{3} \sim 250 \mathrm{ps}\right.$ and $\left.\tau_{2} \sim 2.2 \mathrm{~ns}\right)$, while the longest decay time is constant below $\mathrm{pH}=8\left(\tau_{1}=22 \mathrm{~ns}\right)$ and drops to less than $2 \mathrm{~ns}$ at $\mathrm{pH}=12$. No "nearly constant value of about $8 \mathrm{~ns}$ " is observed. The only similarities with the published data (also shown in Figure $2 \mathrm{a}$ ) are the cation lifetime ( $22 \mathrm{~ns}$ ) (only at $\mathrm{pH}<5$ ) and the $250 \mathrm{ps}$ component, but we see the latter as a rise time at $550 \mathrm{~nm}$ (negative preexponential) for $\mathrm{pH}$ $>10$, as it should be, ${ }^{5}$ and not as a decay time (see Figure $2 \mathrm{~d}$ ).

Kinetic Analysis. When a kinetic system of $n$ species is described by a set of $n$ linear differential equations $(\mathrm{d} \bar{X} / \mathrm{d} t=$ $\bar{K} \bar{X}$, where $\bar{X}$ is the concentration vector and $\bar{K}$ is the rate constant matrix), the time evolution of $\bar{X}$ is modulated by $n$ decay times, whose reciprocals are the eigenvalues of $\bar{K} .^{5}$ For norharmane $(\mathrm{pH}<12)$, there are three species and therefore there should be three decay times as we observe. The evaluation of the nine rate constants which are involved demands extremely accurate data, due to error propagation even when (i) three out of them can be measured directly (the three reciprocal fluorescence lifetimes of $N^{*}, C^{*}$, and $Z^{*}$ ), (ii) the decays are measured as a function of the $\mathrm{pH}$, and (iii) the time-resolved data are coupled to steady-state fluorescence data. The system is not "overdefined", ${ }^{1}$ because some of the rate constants depend on the $\mathrm{pH}$ (see ref 5 for details). Therefore, on the basis of all the

\footnotetext{
* To whom correspondence should be addressed.

† Instituto de Tecnologia Quimica e Biologica.

‡ Universidade de Coimbra.

$\S$ Departamento de Quimica do I.S.T.
}
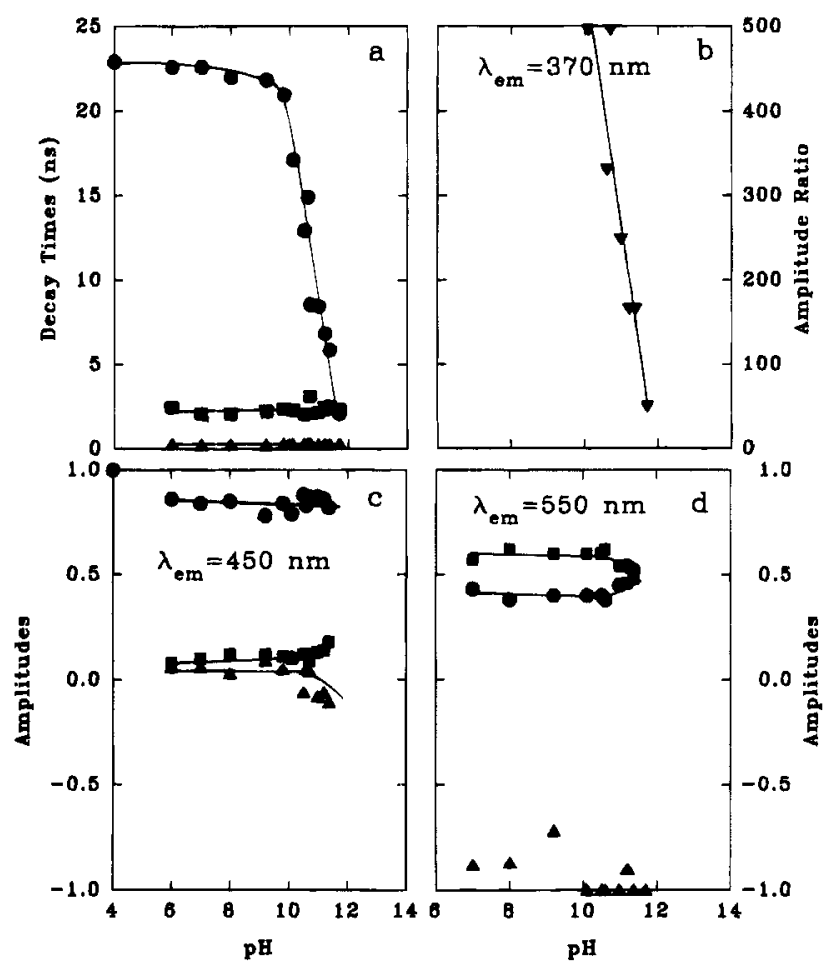

Figure 2. Time-resolved fluorescence data for norharmane in $\mathrm{H}_{2} \mathrm{O}$ at $21^{\circ} \mathrm{C}$ as a function of the $\mathrm{pH}$ : (a) decay times (global analysis ${ }^{5}$; (b) amplitude ratio, $A_{3} / A_{1}$, at $370 \mathrm{~nm}$; (c) normalized amplitudes at 450 $\mathrm{nm}$; (d) normalized amplitudes at $550 \mathrm{~nm}$

considerations given herein, we do not think that the 20 rate constants given in Table 3 of ref 1 can have any real significance.

\section{References and Notes}

(1) Draxler, S.; Lippitsch, M. J. Phys, Chem. 1993, 97, 11493.

(2) Dias, A.; Varela, A. P.; Miguel, M. G.; Maçanita, A. L.; Becker, R. S. J. Phys. Chem. 1992, 96, 10290.

(3) Pardo, A.; Reyman, D.; Martin, E.; Poyato, J. M. L.; Camacho, J. J.; Hidalgo, J.; Sanches, M. J Lumin 1988, 42, 163.

(4) Hidalgo, J.; Roldan, E.; Gonsalez-Arjona, D.; Sanchez, M. J. Photochem. Photobiol. 1987, 41, 103. 556

(5) Seixas de Melo, J.; Maçanita, A. L. Chem. Phys. Lett. 1993, 204, 